ACCEPTED MANUSCRIPT

\title{
Graphene-engineered automated sprayed mesoscopic structure for perovskite device scaling-up.
}

To cite this article before publication: Babak Taheri et al 2018 2D Mater. in press https://doi.org/10.1088/2053-1583/aad983

\section{Manuscript version: Accepted Manuscript}

Accepted Manuscript is "the version of the article accepted for publication including all changes made as a result of the peer review process, and which may also include the addition to the article by IOP Publishing of a header, an article ID, a cover sheet and/or an 'Accepted

Manuscript' watermark, but excluding any other editing, typesetting or other changes made by IOP Publishing and/or its licensors"

This Accepted Manuscript is @ 2018 IOP Publishing Ltd.

During the embargo period (the 12 month period from the publication of the Version of Record of this article), the Accepted Manuscript is fully protected by copyright and cannot be reused or reposted elsewhere.

As the Version of Record of this article is going to be / has been published on a subscription basis, this Accepted Manuscript is available for reuse under a CC BY-NC-ND 3.0 licence after the 12 month embargo period.

After the embargo period, everyone is permitted to use copy and redistribute this article for non-commercial purposes only, provided that they adhere to all the terms of the licence https://creativecommons.org/licences/by-nc-nd/3.0

Although reasonable endeavours have been taken to obtain all necessary permissions from third parties to include their copyrighted content within this article, their full citation and copyright line may not be present in this Accepted Manuscript version. Before using any content from this article, please refer to the Version of Record on IOPscience once published for full citation and copyright details, as permissions will likely be required. All third party content is fully copyright protected, unless specifically stated otherwise in the figure caption in the Version of Record.

View the article online for updates and enhancements. 


\title{
Graphene-engineered automated sprayed mesoscopic structure for perovskite device scaling-up.
}

\author{
Babak Taheri ${ }^{1}$, Narges Yaghoobi Nia ${ }^{1}$, Antonio Agresti ${ }^{1,}{ }^{*}$, Sara Pescetelli ${ }^{1}$, Claudio \\ Ciceroni ${ }^{1}$, Antonio Esaù Del Rio Castillo ${ }^{2}$, Lucio Cinà ${ }^{3}$, Sebastiano Bellani ${ }^{2}$, \\ Francesco Bonaccorso ${ }^{2,4^{*}}$, Aldo Di Carlo ${ }^{1,5^{*}}$
}

${ }^{1}$ CHOSE - Centre for Hybrid and Organic Solar Energy, Department of Electronic Engineering, University of Rome Tor Vergata, via del Politecnico 1, 00133, Rome, Italy;

${ }^{2}$ Graphene Labs, Istituto Italiano di Tecnologia, via Morego 30, 16163 Genoa, Italy

${ }^{3}$ CICCI RESEARCH S.R.L., Grosseto (Italy)

${ }^{4}$ BeDimensional Srl., Via Albisola 121, 16163 Genova, Italy

${ }^{5}$ Department of semiconductor electronics and device physics, National University of Science and Technology “MISiS”, Leninskii pr.4, Moscow 119049, Russia

\begin{abstract}
One of the most thrilling developments in the photovoltaic field over recent years has been the use of organic-inorganic lead halide perovskite, such as $\mathrm{CH}_{3} \mathrm{NH}_{3} \mathrm{PbI}_{3}\left(\mathrm{MAPbI}_{3}\right)$, as a promising new material for low-cost and highly efficient solar cells. Despite the impressive power conversion efficiency (PCE) exceeding 22\% demonstrated on lab-scale devices, large-area material deposition procedures and automatized device fabrication protocols are still challenging to achieve high-throughput serial manufacturing of modules and panels. In this work, we demonstrate that spray coating is an effective technique for the production of mesoscopic small- and large-area perovskite solar cells (PSCs). In particular, we report a sprayed graphene-doped mesoporous $\mathrm{TiO}_{2}\left(\mathrm{mTiO}_{2}\right)$ scaffold for mesoscopic PSCs. By successfully combining the spray coating technique with the insertion of graphene additive into the sprayed $\mathrm{mTiO}_{2}$ scaffold, a uniform deposition and a significant enhancement of the electron transport/injection at the $\mathrm{mTiO}_{2} /$ perovskite electrode is achieved. The use of graphene flakes on the sprayed scaffold boosts the PCE of small-area cells up to $17.5 \%$ that corresponds to an increase of more than $15 \%$ compared to standard cells. For large-area $\left(1.1 \mathrm{~cm}^{2}\right)$ cells, a PCE up to $14.96 \%$ is achieved. Moreover, graphene-doped $\mathrm{mTiO}_{2}$ layer enhances the stability of the PSCs compared to standard devices. The feasibility of PSC fabrication by spray coating deposition of the mesoporous film on large-area $21 \times 24 \mathrm{~cm}^{2}$ provides a viable and low-cost route to scale up the manufacturing of low-cost, stable and highefficiency PSCs.
\end{abstract}

Keywords: Automated Spray Coating, Perovskite Solar Cell, Graphene, mesoporous $\mathrm{TiO}_{2}$, interface engineering 


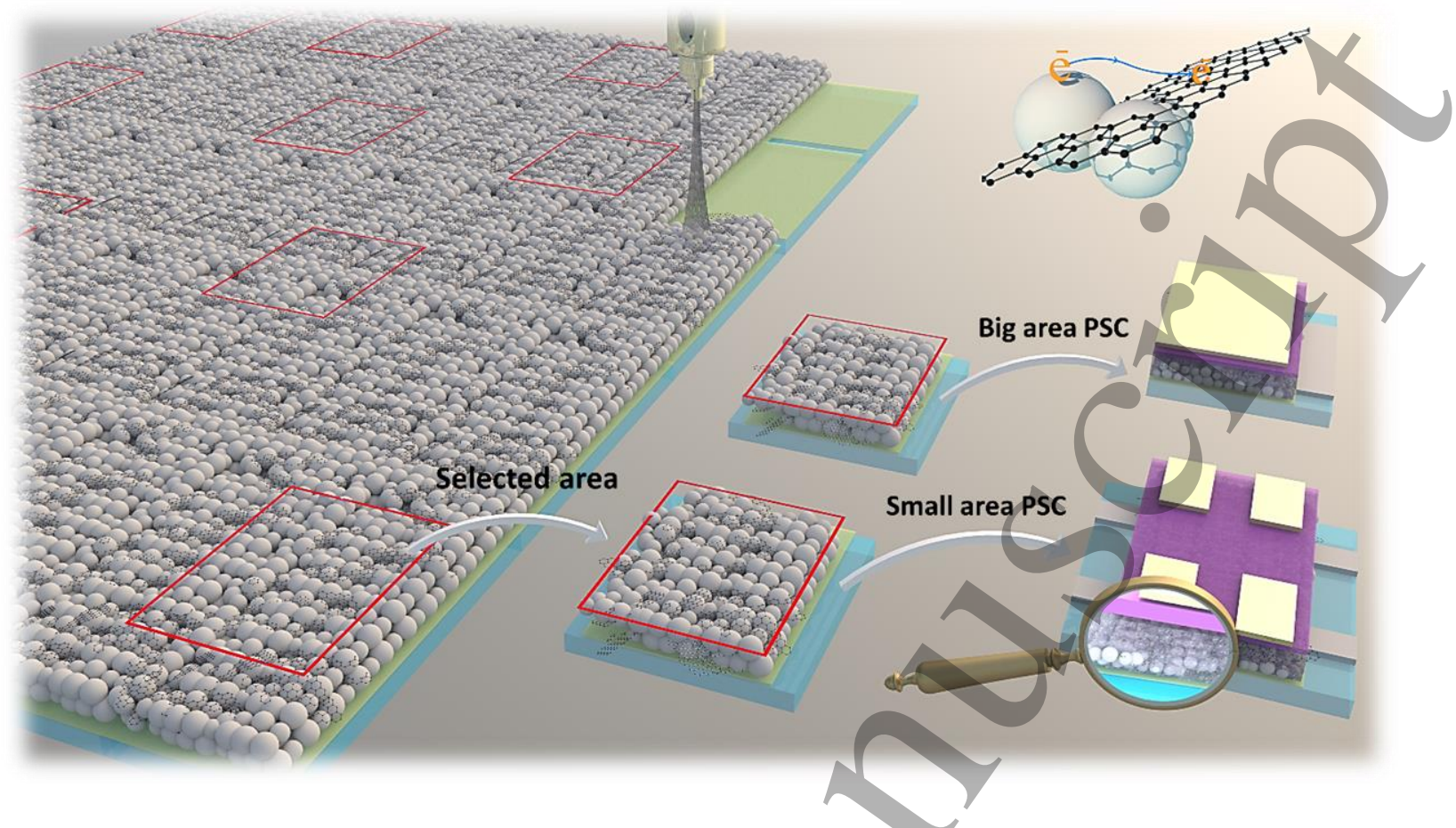

\section{Introduction}

The power conversion efficiency (PCE) of solutionprocessed solar cells underwent a rapid progress, especially in the case of the organic-inorganic hybrid perovskite solar cells (PSCs), showing a record high PCE value of 22.7\% in 2017 [1]. A prototypical PSC architecture comprises an organometal halide perovskite-based light-harvesting layer, sandwiched between a hole-transporting layer (HTL) and an electron-transporting layer (ETL). [2, 3] In particular, for the so-called mesoscopic structure, a mesoporous $\mathrm{TiO}_{2}\left(\mathrm{mTiO}_{2}\right)$ ETL is usually deposited onto a compact $\mathrm{TiO}_{2}\left(\mathrm{cTiO}_{2}\right)$ holeblocking layer as photoelectrode (PE) scaffold. The $\mathrm{mTiO}_{2}$ layer has a dual role consisting in both extracting the photogenerated electrons from the perovskite layer and transporting the charge towards the transparent conductive oxide (TCO) [2, $3]$. The mesoporous scaffold structure accelerates the charge separation and the electron injection from the perovskite to the ETL [4], which allows the most efficient [5] and stable [6] PSCs to be fabricated. The photovoltaic performance achieved by PSCs with mesoscopic $\mathrm{TiO}_{2}$ architectures (PCE > 20\%) [7, 8 ] is encouraging the scientific community to scale up this technology. The possibility to fabricate large-area mesoscopic PSCs has already been proved in our recent work on graphenebased modules by adopting spin coating-based manufacturing. However, in this case, the module dimension is limited by the spin coater dimensions, which restricts the module active area to a few tens of $\mathrm{cm}^{2}[9,10]$. Alternative deposition techniques, such as screen printing [11], blade coating [12], spray coating [13] and electrospray coating [14, 15], have been considered with efficiency on small area cells of $9.3 \%, 9.7 \%, 16 \%$ and
$15 \%$, respectively. However, their applicability to large-area format compatibly with the controlled deposition of uniform $\mathrm{mTiO}_{2}$ films is still an open issue [15].

Differently from a wet film deposition (typical of spin and blade coâting, as well as screen printing techniques), during spray coating of $\mathrm{mTiO}_{2}$ films, small droplets of material are deposited onto the substrate [16]. Consequently, spray coating is not affected by the roughness of the underlying layer or by the substrate pattern [17] and it can be applied on irregular surfaces with high reproducibility [18]. Moreover, it allows the whole device area to be covered in a second timespan without any restriction in term of dimensions and geometry. Lastly, the possibility to spray any solution independently by the mixed precursors or doping materials makes the spray coating advisable to speed up and scale up the perovskite modules fabrication [13, 19] for their market entry [20-22]. Based on these considerations, Huang et al. [13] demonstrated superior charge transport properties for sprayed $\mathrm{mTiO}_{2}$ nanoparticles compared to the corresponding spin-coated film, allowing PSCs to reach PCE higher than 16\%. Moreover, PCE above $15 \%$ has been recently demonstrated for small-area PSCs based on electrospray-coated $\mathrm{mTiO}_{2}$ as PE scaffold [15]. Despite these advances, the application of spray coating techniques to large-area PSCs is still limited to few cases [2325], and the all-sprayed devices achieved PCEs which are still far $(\leq 11.7 \%)$ from the state-of-the-art [1]. Recently, both PCE and the stability of PSCs have been improved by exploiting 2D materials, e.g., graphene or $\mathrm{MoS}_{2}$, to control the interface properties between the different layers in the PSC architecture $[9,10]$. The advantage of this strategy, named as "Graphene Interface Engineering" (GIE), is linked with the possibility to 
create and design layered artificial structures with on-demand electrochemical properties [26-30] by means of scalable, costeffective and solution-processed methods [31-36]. In fact, the possibility to produce 2D materials from the exfoliation of their bulk counterparts in suitable liquids [37-43] enables functional inks to be formulated [44-47]. Subsequently, 2D material inks can be deposited on different substrates by wellestablished printing/coating techniques [48-53].

Based on the aforementioned considerations, graphenebased hole-blocking layer (or ETL) have demonstrated to reduce the energy barriers for electron collection at the PE, improving the short-circuit current density $\left(\mathrm{J}_{\mathrm{SC}}\right)$ [54-56]. For example, graphene/metal oxide composites improved the $\mathrm{J}_{\mathrm{SC}}$ of $23 \%$ compared to the one of graphene-free counterpart [54]. Graphene quantum dots (GQDs) and a lithium neutralized graphene oxide (GO-Li) have been used as interlayers between $\mathrm{mTiO}_{2}$ and perovskite absorber in a mesoscopic PSCs $[55,56]$ to accelerate the electron injection. Consequently, GQDs-based PSCs exhibit faster electron extraction time (90106 ps) if compared with the PSCs without GQD (260-307 $\mathrm{ps}$ ), while the use of GO-Li improved the linear trend of $\mathrm{J}_{\mathrm{SC}^{-}}$ $P_{\text {inc }}$ curves with respect to that expressed by the reference cells. Additionally, graphene has also been used to dope the $\mathrm{mTiO}_{2}$ $[57,58]$. Actually, the presence of graphene into $\mathrm{mTiO}_{2}$-based ETLs reduced the interfacial resistance and improved the electron collection efficiency at the PE by demonstrating around a two-fold faster electron diffusion coefficient than the native ETL [57]. In particular, graphene-doped $\mathrm{mTiO}_{2}(\mathrm{Gr}-$ $\mathrm{mTiO}_{2}$ ) layer deposited by spin coating has shown a record PCE above $16 \%$ and also improved stability, retaining more than $88 \%$ of the initial performance over $16 \mathrm{~h}$ of prolonged 1 SUN illumination at maximum power point (MPP) [58]. Actually, it is well-established that GIE is also an effective tool for the fabrication of efficient and durable PSCs [59].

Herein, we report the use of the GIE in order to fabricate PSCs via Automated Spray Coating (ASC) technique. The ASC enables $\mathrm{Gr}-\mathrm{mTiO}_{2}$ to be deposited compatibly with highthroughput serial manufacturing of PSCs. The optimization of sprayed $\mathrm{mTiO}_{2}$ is assessed by studying its morphological, structural and electronic properties as a function of the substrate temperature and the concentration of $\mathrm{mTiO}_{2}$ paste. The sprayed $\mathrm{Gr}-\mathrm{mTiO}_{2}$ paste allows PSCs to reach a PCE of $17.5 \%$ and $14.96 \%$ on $0.1 \mathrm{~cm}^{2}$ and $1.1 \mathrm{~cm}^{2}$ active areas, respectively. The use of graphene enables the PSC efficiency to be improved more than $16 \%$ compare to the reference device. Finally, electro-optical analysis exhaustively points out the role of graphene in the electron injection, trap states and charge transporting into the PE. Lastly, we show that the use of graphene into the $\mathrm{mTiO}_{2}$ partially mitigates the degradation phenomenon at perovskite/ETL interface, thus increasing the PSCs time life under operative conditions.

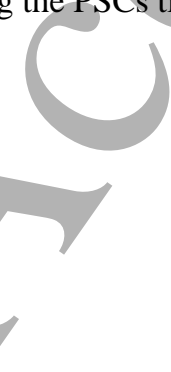

\section{Methods}

\section{Graphene ink preparation}

Liquid phase exfoliation of graphite flakes [60] (SigmaAldrich) in N-methyl-2-pyrrolidone (NMP) and subsequent solvent exchange process [61] were used to prepared graphene flakes ink in ethanol (EtOH, Sigma-Aldrich, + 99.8\%) at a concentration of $0.9 \mathrm{mg} \mathrm{mL}^{-1}$. Experimentally, $3 \mathrm{~g}$ of graphite flakes were dispersed in $300 \mathrm{~mL}$ of NMP and ultrasonicated for $6 \mathrm{~h}$. The obtained dispersion was then ultra-centrifuged at $16000 \mathrm{~g}$ (in a Beckman Coulter Optima ${ }^{\mathrm{TM}}$ XE-90 with a SW32Ti rotor) for $30 \mathrm{~min}$ at $15^{\circ} \mathrm{C}$, exploiting sedimentationbased separation to remove thick flakes and un-exfoliated graphite. After the ultracentrifugation process, $80 \%$ of the supernatant was collected by pipetting. The pipetted sample was dried using a rotary evaporator at $70{ }^{\circ} \mathrm{C}, 5 \mathrm{mbar}$, then 500 $\mathrm{mL}$ of EtOH were added to the dried samples. The sample was then dispersed using a sonic bath for $10 \mathrm{~min}$. Subsequently, the samples were centrifuged at $800 \mathrm{~g}$ (in a Beckman Coulter Optima $^{\text {TM }}$ XE-90 with a SW32Ti rotor). Then, the sediments were collected while the supernatant was discarded. This process of decantation was repeated twice, with the objective to wash out the NMP residuals. Finally, the sediments were dispersed in $200 \mathrm{~mL}$ of $\mathrm{EtOH}$.

\section{Solar cells fabrication}

The solar cells were fabricated on Glass/FTO substrates, which were washed for $10 \mathrm{~min}$ with acetone, deionized water and $\mathrm{EtOH}$, in an ultrasonic bath, consecutively. $\mathrm{A} \mathrm{TiO}_{2}$ dispersion for spray pyrolysis deposition of $\mathrm{cTiO}_{2}$ consisted of $0.16 \mathrm{M}$ diisopropoxytitaniumbis acetylacetonate (TiAcAc) and $0.4 \mathrm{M}$ acetylacetone (AcAc) in $\mathrm{EtOH}$. The final thickness was $50 \mathrm{~nm}$ of the spray pyrolysis at $450^{\circ} \mathrm{C}$ onto the precleaned laser patterned FTO glass. For $\mathrm{mTiO}_{2}$ film deposition, anatase $\mathrm{TiO}_{2}$ nanoparticles paste (18NR-T, Dyesol) was used. The $\mathrm{mTiO}_{2}$ paste was dissolved into EtOH via stirring and ultrasonic bath to obtain $1.4 \mathrm{M}, 1.6 \mathrm{M}, 1.7 \mathrm{M}$ and $1.8 \mathrm{M}$ concentrations. Mesoscopic $\mathrm{TiO}_{2}$ films based on aforementioned concentrations were deposited by ASC technique. Then $0.4 \mathrm{M}$ of TiAcAc was added to the $\mathrm{mTiO}_{2}$ dispersion, which was stirred for $1 \mathrm{~h}$. Then, the obtained dispersion was doped with graphene flakes dispersion in $\mathrm{EtOH}$ (concentration of $0.5 \%, 1 \%$ and $2 \% \mathrm{v} / \mathrm{v}$ were tested). The $\mathrm{mTiO}_{2}$ was then deposited onto the FTO/compact $\mathrm{TiO}_{2}$ substrates through ASC using setting deposition parameters reported in Table $\mathbf{S 1}$. For reference spin-coated $\mathrm{mTiO}_{2}$-based devices, $\mathrm{TiO}_{2}$ paste (18NR-T, Dyesol) was diluted with EtOH, (w/w ratio of 1:5), and spin-coated onto the $\mathrm{cTiO}_{2}$ surface at $1500 \mathrm{rpm}$ for $20 \mathrm{~s}$. The formed $\mathrm{mTiO}_{2}$ films were sintered at $480^{\circ} \mathrm{C}$ for 30 min using a previously reported protocol [62]. The $\mathrm{CH}_{3} \mathrm{NH}_{3} \mathrm{PbI}_{3}$ absorber layer was deposited by a previously reported crystal engineering method in 
a)

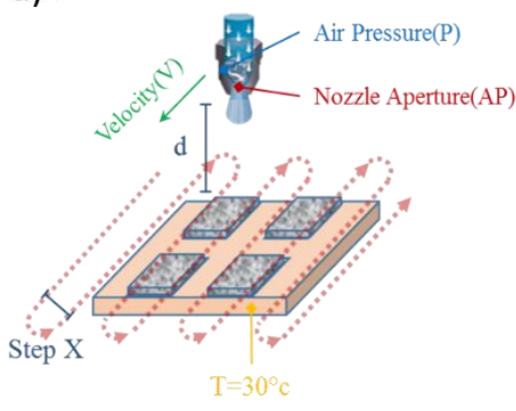

b)

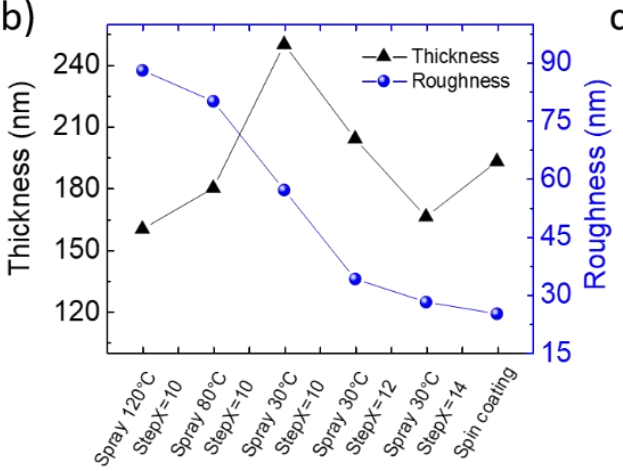

c)

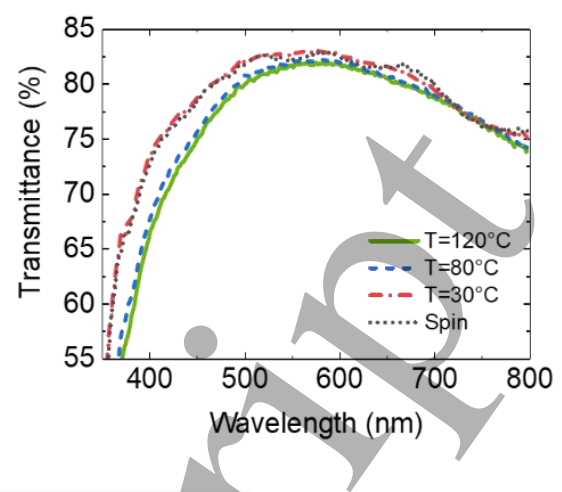

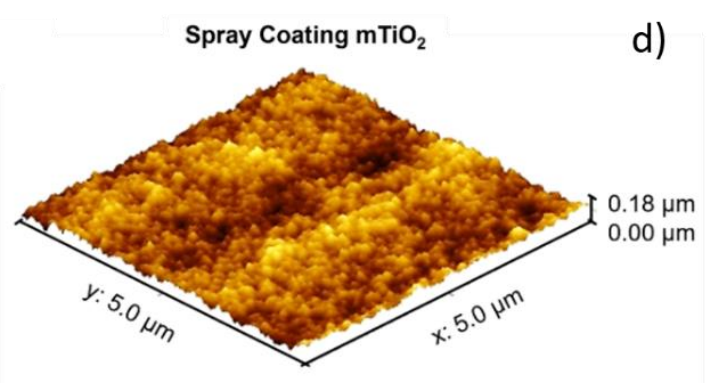

Rms: $22.4 \mathrm{~nm}$

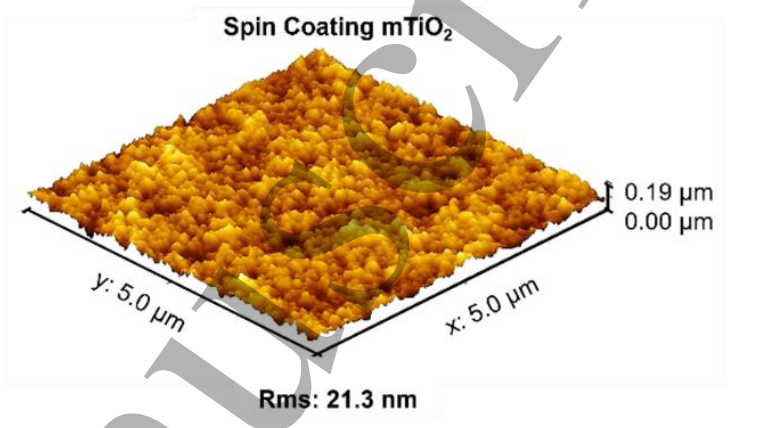

Figure 1. a) Scheme of the Automated Spray Coating. b) Thickness and roughness of $\mathrm{TiO}_{2}$ films, by spray coating deposition at $30^{\circ} \mathrm{C}$, $80^{\circ} \mathrm{C}, 120^{\circ} \mathrm{C}$ and by spin coating one. c) Transmittances of $\mathrm{TiO}_{2}$ film spray-coated on different temperature of substrate. d) AFM topography of the different $\mathrm{mTiO}_{2}$ thin films prepared by ASC at $30^{\circ} \mathrm{C}$ (left) and by spin coating (right).

atmospheric condition [62]. Briefly, $535 \mathrm{mg}$ of $\mathrm{PbI}_{2}$ powder was dissolved in $1 \mathrm{ml}$ DMF and spin-coated at $6000 \mathrm{rpm}$ for $10 \mathrm{~s}$, while the temperature of the solution was set to $70^{\circ} \mathrm{C}$, on the surface of the preheated $\left(70{ }^{\circ} \mathrm{C}\right) \mathrm{mTiO}_{2}$ film. Subsequently, the devices were annealed at $40^{\circ} \mathrm{C}$ for $2 \min$ (temperature raise time $=1 \mathrm{~min})$ ) and at $60^{\circ} \mathrm{C}$ for $1 \mathrm{~min}$ (temeperature raise time $=1 \mathrm{~min}$ ). In the second step, the cooled $\mathrm{PbI}_{2}$ layers were dipped in a solution of methylammonium iodide $\left(\mathrm{CH}_{3} \mathrm{NH}_{3} \mathrm{I}\right.$ in anhydrous 2-propanol $10 \mathrm{mg} \mathrm{mL}^{-1}$ ) for $10 \mathrm{~min}$ at room temperature while the solution was kept under mechanical stirring during the dipping time. Then, the devices were washed immediately by spin coating 2-propanol with an acceleration rate of $6000 \mathrm{rpm}$ for $10 \mathrm{sec}$. Finally, the devices were heated at $70^{\circ} \mathrm{C}$ for $2 \mathrm{~min}$ (temperature raise time $=1 \mathrm{~min}$ ), and at $115{ }^{\circ} \mathrm{C}$ for $4 \mathrm{~min}$ (temperature raise time $=3 \mathrm{~min}$ ) with relative humidity of about $40 \%$ on a hotplate. After heat treatment, $100 \mu \mathrm{l}$ of spiroOMeTAD (73.5 mg ml-1) in chlorobenzene (CB) solution doped with $26 \mu \mathrm{l}$ of tert-butylpyridine (TBP), $16.6 \mu \mathrm{l}$ of Lithium Bis (Trifluoromethanesulfonyl) Imide (Li-TFSI) of stock solution (520 mg in $1 \mathrm{ml}$ acetonitrile), and $7.2 \mu \mathrm{l}$ of cobalt (III) complex solution (FK209 from Lumtec) was deposited as HTL by spin coating at $2000 \mathrm{rpm}$ for $20 \mathrm{~s}$. Finally, $80 \mathrm{~nm}$ of Au was deposited as counter electrode by thermal evaporation.

\section{Characterization}

Masked devices were tested by acquiring I-V curves under a Class A solar simulator (ABET Sun 2000) at AM1.5 and 100 $\mathrm{mW} \mathrm{cm}^{2}$ illumination conditions calibrated with a reference silicon cell (RERA Solutions RR-1002), using a Keithley 2420 as a source-meter in ambient condition without sealing. Sun simulator spectrum and class were measured with a BLACK-Comet UV-VIS Spectrometer.

The atomic force microscopy (AFM) analysis of the surface of the $\mathrm{TiO}_{2}$ thin films realized by spray and spin coating, was performed through an A.P.E. Research Atomic Force Microscope. Measurements were performed in non-contact mode with a silicon tip with a radius of $8 \mathrm{~nm}$, mounted on a cantilever (resonance frequency $=325 \mathrm{kHz}$ ) with a spring constant of $40 \mathrm{~N} \mathrm{~m}^{-1}$.

Dark I-V, transient photovoltage (TPV), stability stress test at the MPP, and illumination intensity dependence of the $\mathrm{V}_{\text {oc }}$ and $\mathrm{J}_{\mathrm{sc}}$ were performed with a high speed four channel source meter. A white LED array (4200 Kelvin) tuneable up to 200 $\mathrm{mWcm}^{2}$ of optical power density-based measurement system 
a)

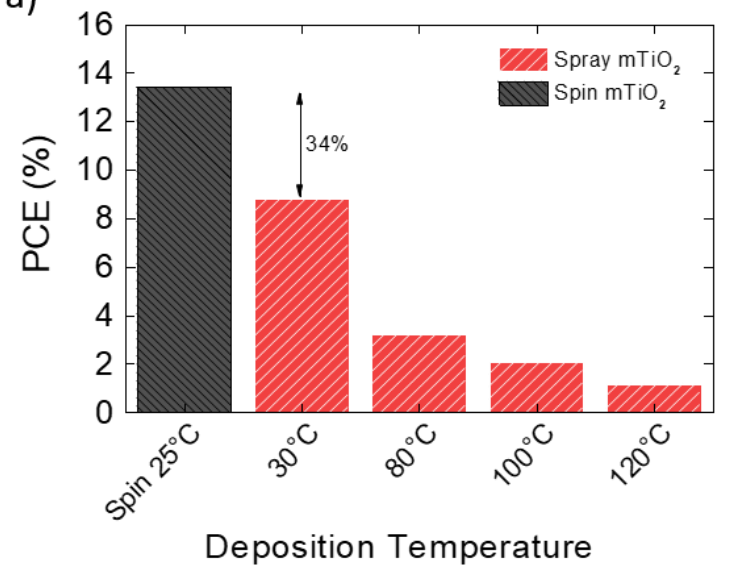

b)

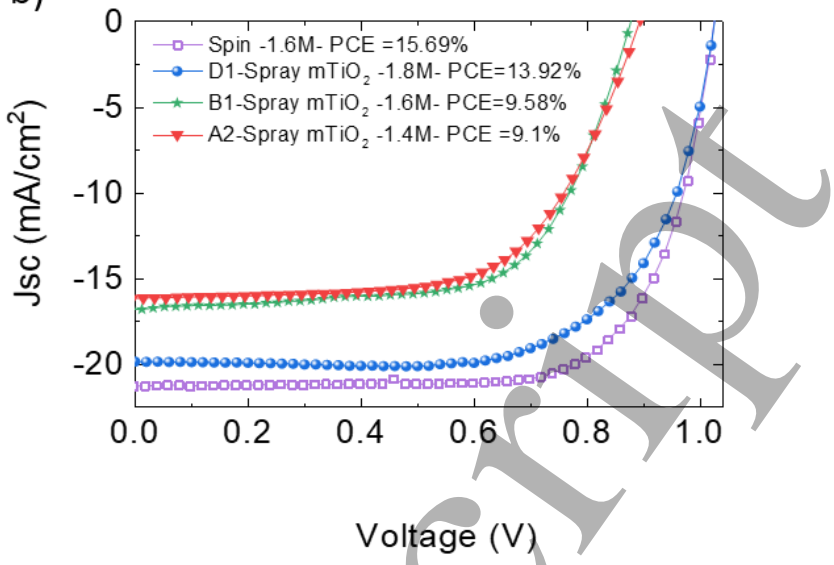

Figure 2. a) PCE under $1 \mathrm{SUN}$ illumination for sprayed-mTiO ${ }_{2}$-based PSCs, realized by varying the substrate deposition temperature. b) Density of current-voltage (I-V) curves under 1 sun for complete PSCs realized by using three different $\mathrm{mTiO}_{2}$ dispersion concentrations with optimum deposition setting.

(Arkeo-Cicci research s.r.1.) was used as light source. A spring contact-based sample holder was used to improve the repeatability of the experiments.

Incident power conversion efficiency (IPCE) spectra were aquired by using a homemade setup.

Electrochemical measurements were performed in dark conditions at room temperature using an Auto-lab 302N Modular Potentiostat from Met Rohm in the two-electrode configuration with a bias voltage ranging from 0.6 to $1 \mathrm{~V}$. The sinewave perturbation used was $10 \mathrm{mV}$ of amplitude with frequencies from $1 \mathrm{MHz}$ to $1 \mathrm{~Hz}$.

The surface morphology of mesoporous layers and cross section image were obtained by using Scanning Electron Microscope (SEM) FE-SEM ZEISS.

\section{Results and Discussion}

In mesoscopic PSCs, the light enters from the PE to excite the photoactive layer. Therefore, the light passes through the $\mathrm{mTiO}_{2}$ layer before reaching the perovskite over-layer. For this reason, the control of optical transparency, thickness and roughness of the $\mathrm{TiO}_{2}$ film are crucial to achieve efficient PSCs [63, 64].

The morphological and optoelectronic properties of the final sprayed $\mathrm{mTiO}_{2}$ layer depend by several deposition parameters, i.e., the substrate temperature, the number of spray cycles, the distance between the spray nozzle and the substrate, the nozzle aperture, the air pressure, and, lastly, the distance between two adjacent spray lines (StepX).[65, 66] (see Figure 1a).

As a first step in the deposition optimization of the ASC process, we studied the influence of the substrate (FTO) temperature on the roughness and transparency of the resultant $\mathrm{mTiO}_{2}$ layer. Spin coating deposition of $\mathrm{mTiO}_{2}$ was also considered for comparison. Spray coating of commercial
$\mathrm{mTiO}_{2}$ nanoparticles (18NRT) dispersed in EtOH $(1: 5 \mathrm{w} / \mathrm{w}$ ratio) was accomplished on the substrate heated at different temperatures $\left(30^{\circ} \mathrm{C}, 80^{\circ} \mathrm{C}\right.$ and $\left.120^{\circ} \mathrm{C}\right)$. As shown in Figure $\mathbf{1 b}, \mathbf{c}$, the highest substrate temperature $\left(120^{\circ} \mathrm{C}\right)$ resulted in a rough $\mathrm{mTiO}_{2}$ surface $(>80 \mathrm{~nm})$, which caused a decrease of the average electrode transmittance $(81.4 \%)$ with respected to that obtained for the other temperatures $\left(83 \%\right.$ for $\mathrm{mTiO}_{2}$ obtained by spray at $30^{\circ} \mathrm{C}$ and spin coating). On the other hand, the low substrate temperatures $\left(30\right.$ and $80{ }^{\circ} \mathrm{C}$ ) allowed the solvent to reach the substrate surface with a consequent flattening of the $\mathrm{mTiO}_{2}$ surface. Notably, the RMS roughness of the layer was also influenced by the overlap of two adjacent spray lines. the $\mathrm{mTiO}_{2}$ film deposited by using a distance between two adjacent spray lines of $14 \mathrm{~mm}($ StepX $=14 \mathrm{~mm})$ had the best width overlay of each sprayed spot $(5 \mathrm{~mm})$, since it results in lower roughness $(28 \mathrm{~nm})$ with respect to other StepX values. Atomic force microscopy topographies (Figure 1d) show that the sample realized by ASC had a root means square (RMS) roughness $(22.4 \mathrm{~nm})$ comparable to that of the spin-coated samples (21.3 nm) (see also Table S2).

The $\mathrm{mTiO}_{2}$ film morphology obtained for the deposition at $30{ }^{\circ} \mathrm{C}$ enabled the PSCs performance to be enhanced compared to that of the PSCs produced with higher temperatures, i.e., 80, 100 and $120^{\circ} \mathrm{C}$ (Figure 2a). More in detail, the PCE decreased by almost $60 \%$ and $80 \%$ when the substrate temperature for the $\mathrm{mTiO}_{2}$ spray coating increased from 30 to $80{ }^{\circ} \mathrm{C}$ and $120{ }^{\circ} \mathrm{C}$, respectively. However, it is noteworthy that the highest PCE obtained for sprayed $\mathrm{mTiO}_{2}$ based PSCs (13.92\%) was still 34\% lower than that of reference PSCs produced by spin coating $\mathrm{mTiO}_{2}(15.69 \%)$.

In order to optimize the sprayed $\mathrm{mTiO}_{2}$ layer morphology, different concentrations of $\mathrm{TiO}_{2}$ dispersion (1.4 M, 1.6 M, 1.7 $\mathrm{M}$ and $1.8 \mathrm{M}$ ) were employed and titanium diisopropoxide bis acetylacetonate (TiAcAc) was added to the sprayed dispersion

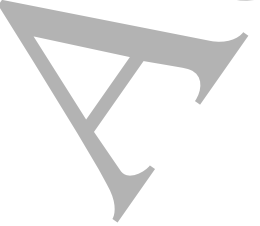




\begin{tabular}{|c|c|c|c|c|c|}
\hline Cell Type & $\begin{array}{l}V_{o c} \\
\text { (V) }\end{array}$ & $\begin{array}{c}\mathrm{J}_{\mathrm{sc}} \\
\left(\mathrm{mA} / \mathrm{cm}^{2}\right)\end{array}$ & $\begin{array}{l}\mathrm{FF} \\
(\%)\end{array}$ & $\begin{array}{l}\text { PCE } \\
(\%)\end{array}$ & $\begin{array}{l}\mathrm{J}_{\mathrm{sc}} \text { form integrated IPCE } \\
\left(\mathrm{mA} / \mathrm{cm}^{2}\right)\end{array}$ \\
\hline $\begin{array}{l}\text { A2 Spray coating } 1.4 \mathrm{M} \\
\text { (nozzle } A P=8, P=1.5 \text { bar) }\end{array}$ & 0.871 & -15.88 & 66.34 & 9.18 & -14.95 \\
\hline $\begin{array}{l}\text { Spray coating } 1.6 \mathrm{M} \text { without TiAcAc } \\
\text { (nozzle } A P=9, P=1.5 \text { bar) }\end{array}$ & 0.857 & -15.41 & 65.80 & 8.69 & -14.67 \\
\hline $\begin{array}{l}\text { B1 Spray coating } 1.6 \mathrm{M} \\
\text { (nozzle AP=9, } P=1.5 \text { bar) }\end{array}$ & 0.873 & -16.60 & 66.10 & 9.58 & -16.09 \\
\hline $\begin{array}{l}\text { D1 Spray coating } 1.8 \mathrm{M} \\
\text { (nozzle } A P=9, P=1 \text { bar) }\end{array}$ & 1.021 & -19.77 & 68.94 & 13.92 & \\
\hline Standard Spin coating & 1.018 & -21.16 & 72.82 & 15.69 & \\
\hline
\end{tabular}

Table 1. PSCs $\mathrm{V}_{\mathrm{OC}}, \mathrm{J}_{\mathrm{SC}}, \mathrm{FF}$ and PCE values for three different $\mathrm{mTiO}_{2}$ dispersion concentrations with about $180 \mathrm{~nm}$ of sprayed $\mathrm{mTiO}_{2}$ thickness, compared with those of standard spin-coated $\mathrm{mTiO}_{2}$-based cells. Deposition have been performed with $30^{\circ} \mathrm{C}$ of substrate temperature and with StepX of $14 \mathrm{~mm}$.

to improve the connectivity between the $\mathrm{mTiO}_{2}$ nanoparticles [13] (details about the analysed concentrations are reported in the methods section). By adjusting spray parameter settings, (Table S1), the $\mathrm{mTiO}_{2}$ film with thicknesses ranging from 150 to $200 \mathrm{~nm}[5,67,68]$ exhibited the lowest RMS roughness values (about $22 \mathrm{~nm}$ ) (Figure S1). Therefore, small-area (0.1 $\mathrm{cm}^{2}$ ) PSCs were produced with a $\mathrm{mTiO}_{2}$ film thicknesses of $180 \mathrm{~nm}$, as shown by a representative cross-sectional SEM image (Figure S2). The as-prepared cells without TiAcAc resulted in maximum PCE of $9.1 \%$. The addition of TiAcAc into $\mathrm{mTiO}_{2}$ dispersion resulted in a cell PCE improvement of $+10 \%$ (Table 1). Notably, the highest average PCE of $13.92 \%$ was achieved for the PSCs produced by using a $\mathrm{mTiO}_{2}$ concentration of 1.8 M. As shown in Figure 2b, the PCE enhancement was a consequence of the higher current density $\left(\mathrm{J}_{\mathrm{sc}}\right)\left(-19.77 \mathrm{~mA} \mathrm{~cm}^{-2}\right)$ and Fill Factor (FF) (69\%) compared with those of the PSCs fabricated with other $\mathrm{mTiO}_{2}$ dispersion concentrations $(1.4 \mathrm{M}, 1.6 \mathrm{M}$ and $1.7 \mathrm{M})$. We assign these effects to an effective crystallization of the perovskite into the 22 nm-rough $\mathrm{mTiO}_{2}$, which help to reduce the carrier recombination and improve carrier transport and collection abilities [69-71].

The pore size for efficient infiltration of the perovskite into the $\mathrm{mTiO}_{2}$ (Error! Reference source not found.) leads to the highest electron mobility and the lowest disorder in the interface with perovskite.

Although the sprayed $\mathrm{mTiO}_{2}$-based PSCs achieved PCE of $\sim 14 \%$, their $\mathrm{J}_{\mathrm{sc}}$ and FF were still $10 \%$ lower than those of spincoated $\mathrm{mTiO}_{2}$-based-based PSCs (Table 1), suggesting that the electron recombination at $\mathrm{mTiO}_{2} /$ perovskite interface significantly affected the cell performance for sprayed $\mathrm{mTiO}_{2}$ based devices compared to that of spin-coated $\mathrm{mTiO}_{2}$-based ones [72, 73].

With the aim to further improve the physical and electrical sprayed $\mathrm{mTiO}_{2}$ film.

With the aim to boost further the performance of the PSCs obtained by ASC the $\mathrm{mTiO}_{2}$ dispersion was enriched with graphene flakes, resulting in hybrid mesoscopic films herein
namedGr- $\mathrm{mTiO}_{2}$ ). Graphene flakes were produced by the LPE [44], in NMP. The synthetic procedure is detailed in [58] and summarized in the Experimental section. Three different concentrations of graphene flakes dispersion $(0.5 \%, 1 \%$ and $2 \% \mathrm{v} / \mathrm{v})$ were tested by fabricating PSCs with area of $0.1 \mathrm{~cm}^{2}$. In agreement with the SEM images of the $\mathrm{mTiO}_{2}$ surface morphology (Figure S3), the Gr-mTiO ${ }_{2}$ films did not show any difference with respect to the pristine $\mathrm{mTiO}_{2}$ films. Moreover, the films, deposited by spray and spin coating have shown the same súrface morphology with an average $\mathrm{mTiO}_{2}$ particle size of $\sim 21 \mathrm{~nm}$.

In term of photovoltaic performance of the PSCs, the optimum concentration of graphene inside $\mathrm{mTiO}_{2}$ was $1 \% \mathrm{v} / \mathrm{v}$, which results in an increase of $\mathrm{J}_{\mathrm{sc}}$ and PCE of $13 \%$ and $23 \%$, respectively, with respect to those of graphene-free reference (Figure S4). This means that a concentration of $1 \% \mathrm{v} / \mathrm{v}$ of graphene dispersion concentration into $\mathrm{mTiO}_{2}$ dispersion can suppress the electron recombination, i.e., to increase the $\mathrm{J}_{\mathrm{sc}}$. However, once graphene concentration exceeded $1 \% \mathrm{v} / \mathrm{v}$, the PSC performance decreased. This trend can be ascribed to the increase of $\mathrm{Gr}-\mathrm{mTiO}_{2}$ light absorption by increasing graphene flakes concentration that strongly affects the optical transmittance of the PE (see Figure S5) [74]. This effect is also observed in the performance of graphene-based cells, in which $\mathrm{J}_{\mathrm{sc}}$ begins to decrease beyond the optimum graphene loading of $1 \%$ v/v (see Figure S4a).

Perovskite solar cells with and without graphene and for both spray and spin coating of $\mathrm{mTiO}_{2}$ were fabricated and compared. To deposit $\mathrm{mTiO}_{2}$ by ASC, the optimized graphene dispersion with a concentration of $1 \% \mathrm{v} / \mathrm{v}$ of was incorporated into the $1.8 \mathrm{M} \mathrm{mTiO}_{2}$ dispersion. In order to demonstrate the uniformity of large-area $\mathrm{mTiO}_{2}$ obtained by ASC, firstly the spray coating was accomplished on a large-area substrate $\left(24 \times 20 \mathrm{~cm}^{2}\right)$. Secondly, the substrate was divided into $2.5 \times 2.5$ $\mathrm{cm}^{2}$ pieces, subsequently selected from different areas of the initial substrate, to finalize the fabrication of entire PSCs. On these substrates, devices were made with different active areas $0.1 \mathrm{~cm}^{2}$ and $1.1 \mathrm{~cm}^{2}$ (herein named small- and large-area 

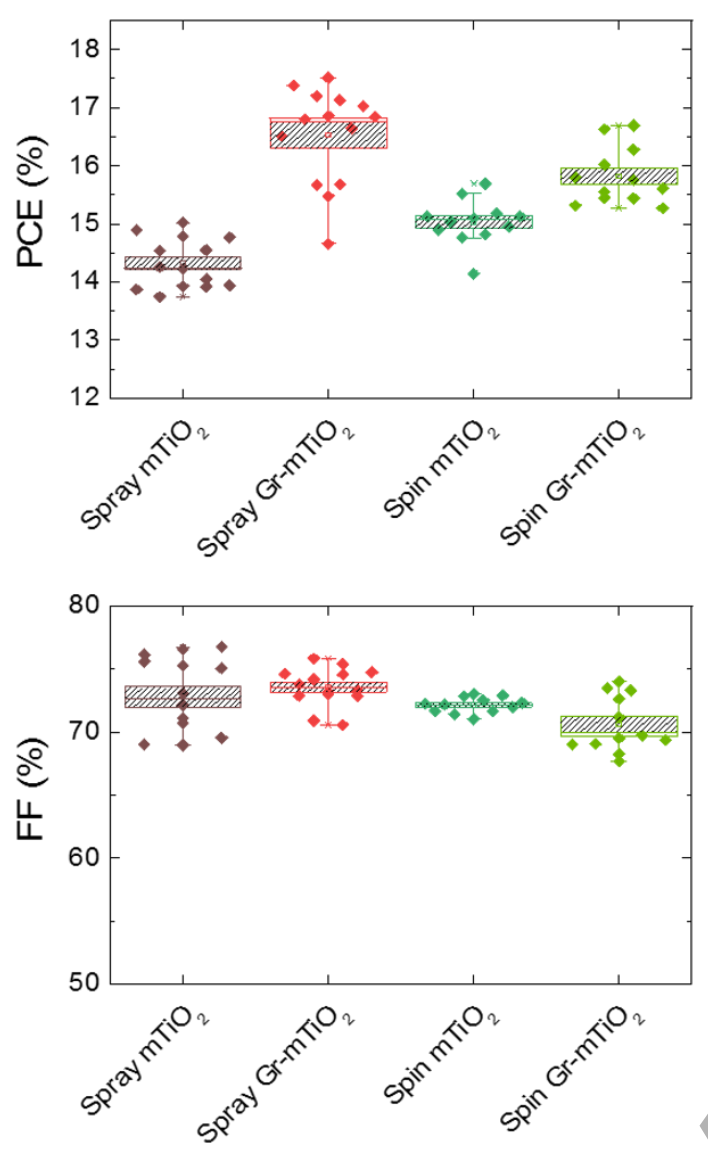
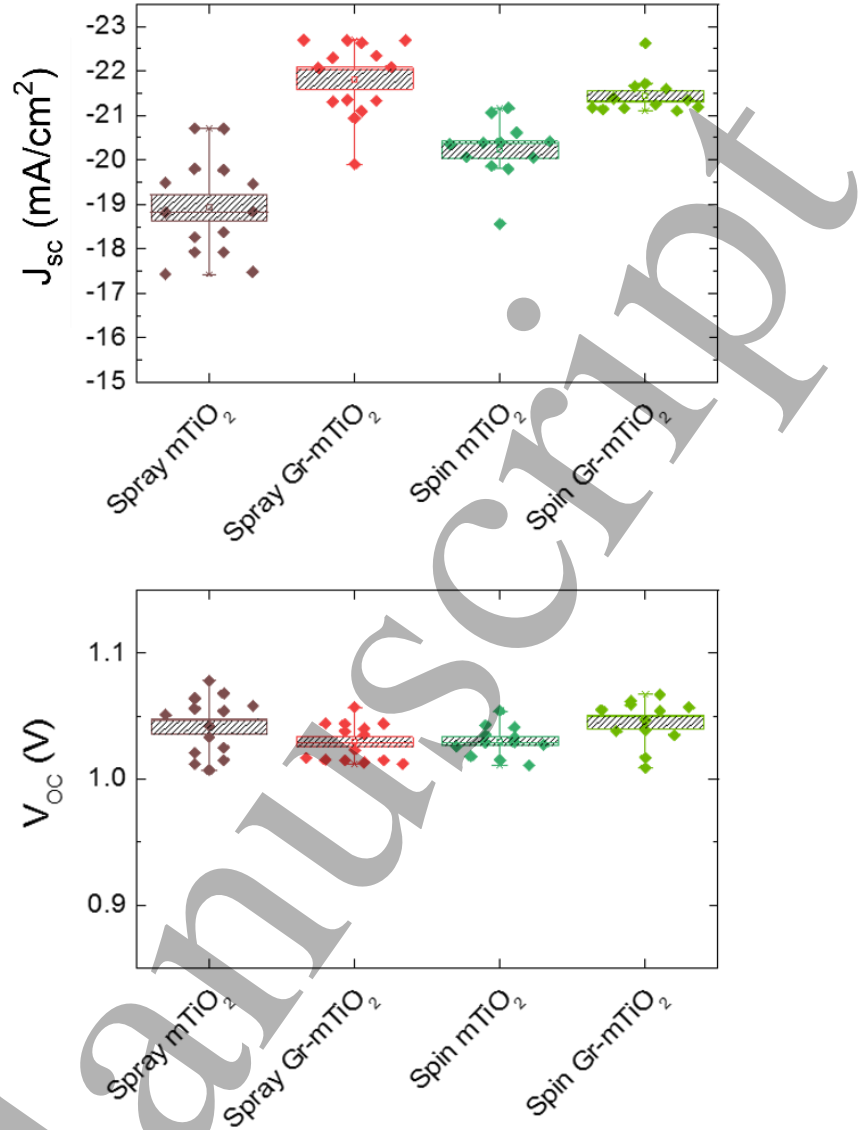

Figure 3. Comparison of electrical parameter statistics for 26 small-arêa $\left(0.1 \mathrm{~cm}^{2}\right)$ PSCs based on pristine $\mathrm{mTiO}_{2}$ and 26 small-area PSCs based on $\mathrm{Gr}_{-} \mathrm{mTiO}_{2}$ scaffold deposited by ASC and spin coating techniques. The cells were measured under/ SUN AM 1.5G illumination.

PSCs, respectively) by using the deposition parameter settings previously optimized (see Methods section for details).

Figure 3 reports the electrical parameters (PCE, $\mathrm{J}_{\mathrm{sc}}$, FF and $\mathrm{V}_{\mathrm{OC}}$ ) for PSCs based on pristine $\mathrm{mTiO}_{2}$ and $\mathrm{Gr}-\mathrm{mTiO}_{2}$ deposited by ACS and spin coating techniques. Notably, for both deposition techniques, the $\mathrm{Gr}-\mathrm{mTiO}_{2}$ led to a significant enhancement of $\mathrm{J}_{\mathrm{sc}}$ with respect to pristine $\mathrm{mTiO}_{2}$. In particular, for small-area cells $\left(0.1 \mathrm{~cm}^{2}\right)$, the spray-deposited
Gr-mTiO $\mathrm{miO}_{2}$ led to a $\sim 16 \%$ increase of $\mathrm{J}_{\mathrm{sc}}$ with respect to the $\mathrm{mTiO}_{2}$-based PSCs, whereas the graphene doping for spincoated $\mathrm{mTiO}_{2}$ improved the $\mathrm{J}_{\mathrm{sc}}$ of $5 \%$ with respect to the graphene-free reference.

The average PCE of spray $\mathrm{Gr}-\mathrm{mTiO}_{2}$ based devices was $16.8 \%$, i.e., higher than the spin-coated $\mathrm{mTiO}_{2}$-based PSCs $(15.6 \%)$. For pristine sprayed $\mathrm{mTiO}_{2}$-based PSC, the average

$\begin{array}{ccccc}\text { Type of cells } & \begin{array}{c}\mathrm{V}_{\mathrm{oc}} \\ (\mathrm{V})\end{array} & \begin{array}{c}\mathrm{J}_{\mathrm{sc}} \\ \left(\mathrm{mA} / \mathrm{cm}^{2}\right)\end{array} & \begin{array}{c}\mathrm{FF} \\ (\%)\end{array} & \begin{array}{c}\mathrm{PCE} \\ (\%)\end{array} \\ \text { Spray Pristine } \mathrm{mTiO}_{2} & 1.063 & -18.571 & 66.712 & 13.165 \\ & (1.05 \pm 0.012) & (-18.91 \pm 0.46) & (65.15 \pm 2.14) & (12.94 \pm 0.26) \\ & 1.059 & -20.199 & 69.957 & 14.963 \\ \text { Spray } \mathrm{Gr}_{2}-\mathrm{mTiO}_{2} & (1.06 \pm 0.005) & (-19.79 \pm 0.43) & (67.25 \pm 2.54) & (14.21 \pm 0.80) \\ \text { Spin } \mathrm{mTiO}_{2} & 1.031 & -17.039 & 65.488 & 11.503 \\ & (1.04 \pm 0.008) & (-18.12 \pm 0.96) & (62.6 \pm 2.50) & (11.78 \pm 0.29) \\ \text { Spin } \mathrm{Gr}_{2}-\mathrm{mTiO}_{2} & 1.030 & -19.224 & 68.199 & 13.506 \\ & (1.04 \pm 0.01) & (-19.02 \pm 0.19) & (65.22 \pm 4.11) & (12.91 \pm 0.91)\end{array}$


a)

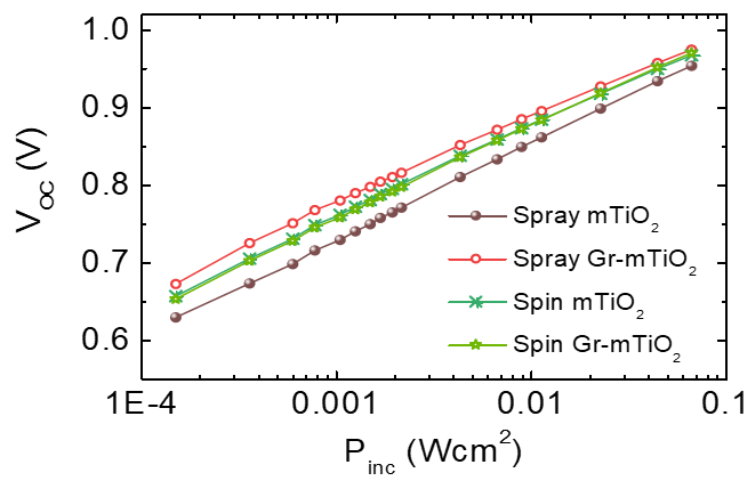

c)

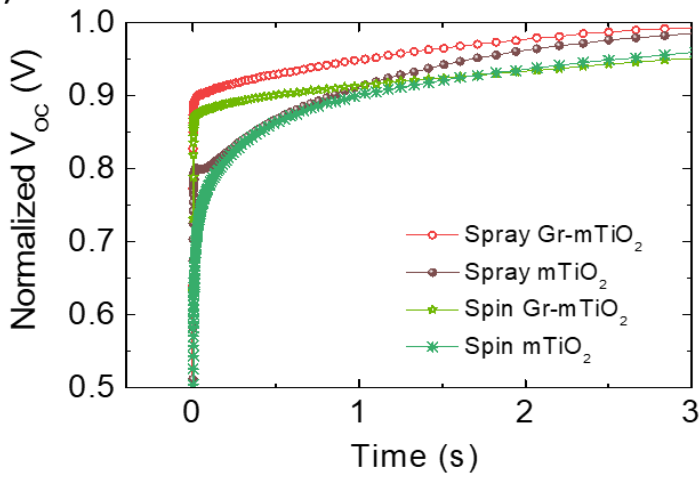

b)

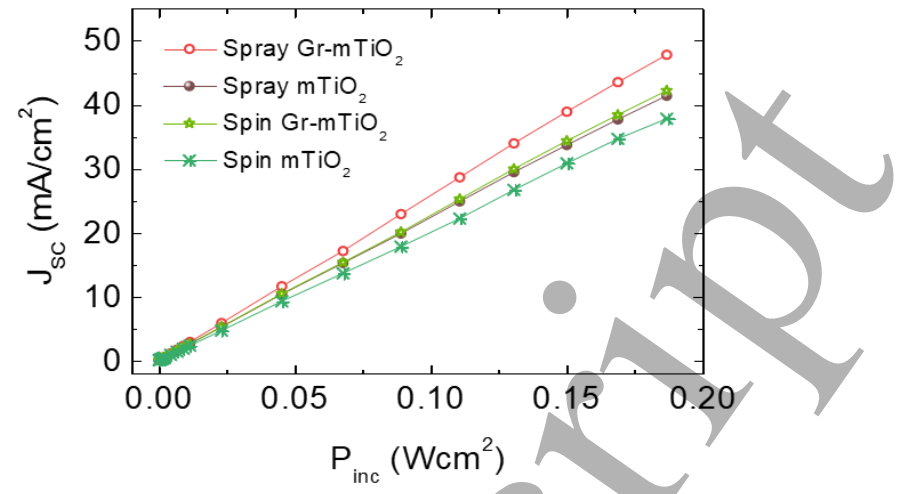

d)

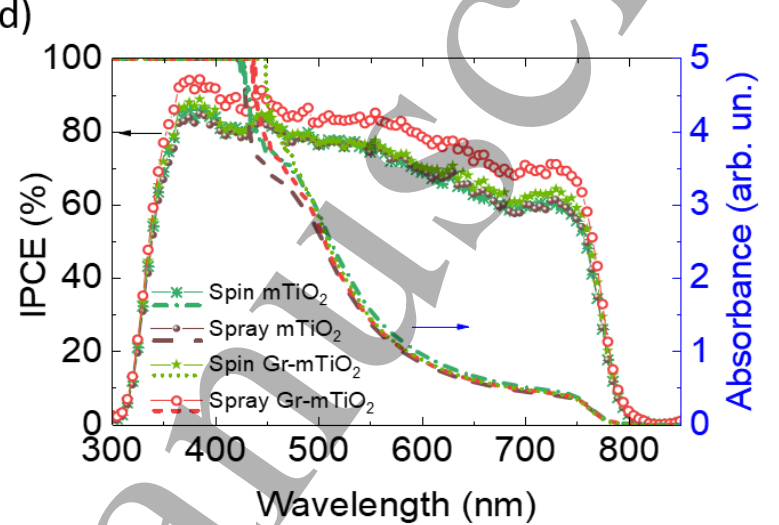

Figure 4. a) VoC vs. Pinc, b) JSC vs. Pinc and c) Voc rise profiles normalized at the maximum value, d) Absorption and IPCE spectra for the tested PSCs.

$\mathrm{J}_{\mathrm{SC}}, \mathrm{FF}$ and $\mathrm{V}_{\mathrm{OC}}$ values were $18.7 \mathrm{~mA} \mathrm{~cm}^{-2}, 0.72$ and $1050 \mathrm{mV}$, respectively. By introducing graphene flakes into the $\mathrm{mTiO}_{2}$, average $\mathrm{J}_{\mathrm{sc}}$ increased up to $22.2 \mathrm{~mA} \mathrm{~cm} \mathrm{c}^{-2}$, while $\mathrm{N}_{\mathrm{oc}}$ and $\mathrm{FF}$ values did not undergo significant variations. Therefore, our champion cell exhibited $17.5 \%$ PCE, exceeding the highest PCE previously reported for a two-step process $\left(0.1 \mathrm{~cm}^{2}\right.$ active area) $\mathrm{CH}_{3} \mathrm{NH}_{3} \mathrm{PbI}_{3}$-based $\mathrm{PSC}$ using spin-coated $\mathrm{mTiO}_{2}$ layer (PCE 17\%) [62, 75].

The characterization of large-area $\left(1.1 \mathrm{~cm}^{2}\right)$ cells (see Table 2 and Figure S6) confirmed the $\mathrm{J}_{\mathrm{sc}}$ enhancement for $\mathrm{Gr}$ $\mathrm{mTiO}_{2}$-based cells with respect to that of pristine $\mathrm{mTiO}_{2}-$ based reference (from -18.5 to $-20.1 \mathrm{~mA} \mathrm{~cm}^{-2}$ ).

Time-dependent PCE response (Figure S7a) and I-V curves as a function of the scan voltage direction (Figure S7b) did not evidence the presence of hysteresis [8].

\section{The role of graphene in $\mathrm{mTiO}_{2}$ film: electro-optical analysis}

With the aim to fully understand the differences between the pristine $\mathrm{mTiO}_{2}$ and the $\mathrm{Gr}-\mathrm{mTiO}_{2}$ based devices, complementary electrical measurements $\left(\mathrm{V}_{\mathrm{oc}} / \mathrm{J}_{\mathrm{sc}}\right.$ vs. light intensity) were performed for each device typology.

The relation between $\mathrm{V}_{\mathrm{oc}}$ and the incident light power $\left(\mathrm{P}_{\text {inc }}\right)$ (Figure 4a) allowed the recombination processes at the $\mathrm{mTiO}_{2}$ /perovskite interface to be evaluated [76, 77]. $\mathrm{V}_{\text {OC }} v s$. $\mathrm{P}_{\mathrm{inc}}$ trends recorded for all the tested device typologies showed a logarithmic increase with similar slope values $\left(124 \mathrm{mV} \mathrm{dec}{ }^{-}\right.$ ${ }^{1}$ for spray reference-mTiO $2,119 \mathrm{mV} \mathrm{dec}{ }^{-1}$ for spray $\mathrm{Gr}-\mathrm{mTiO}_{2}$ and $122 \mathrm{mV} \mathrm{dec}{ }^{-1}$ for spin $\mathrm{mTiO}_{2}$ and spin $\mathrm{Gr}-\mathrm{mTiO}_{2}$ ). This means that $\mathrm{Gr}-\mathrm{mTiO}_{2}$ based ETL did not significantly influence charge recombination rate over a wide operating light intensity window (from $0.1 \mathrm{~mW} \mathrm{~cm}^{-2}$ to $100 \mathrm{~mW} \mathrm{~cm}$ ). The higher $\mathrm{V}_{\mathrm{oc}}$ absolute values recorded for $\mathrm{Gr}-\mathrm{mTiO}_{2}$ based device compared to that of free-graphene devices was correlated with the reduced interfacial charge recombination at $\mathrm{TiO}_{2}$ /perovskite, in accordance with previous reports [78].

5
5
6
5
5

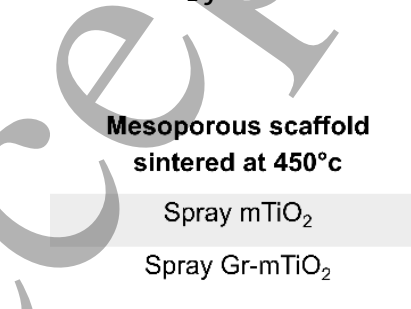

$\begin{gathered}\text { Resistivity } \\ \text { P (ohm cm) }\end{gathered}$
$3.6 \mathrm{E}+5$
$2.4 \mathrm{E}+5$

\section{Conductivity}

$\sigma($ Siemens $\mathrm{cm}$ )

$2.7 \mathrm{E}-6$

$4.2 \mathrm{E}-6$

Table 3. The sheet resistance of pristine $\mathrm{mTiO}_{2}$ and the $\mathrm{Gr}-\mathrm{mTiO}_{2}$, measured by four-point probe system. 
In addition, the variation of $\mathrm{J}_{\mathrm{sc}} v s . \mathrm{P}_{\text {inc }}$ was recorded, as reported in Figure $4 \mathbf{b}$. Since the $\mathrm{J}_{\mathrm{sc}}-\mathrm{P}_{\text {inc }}$ slope increases with the efficiency of charge collection at the device contacts [79], we concluded that sprayed $\mathrm{Gr}-\mathrm{mTiO}_{2}$ layer with $266 \mathrm{~mA} \mathrm{~W}{ }^{-1}$ slope effectively collected the photo-generated electrons from the perovskite absorber. Finally, transient $\mathrm{V}_{\mathrm{oc}}$ rise measurements represented in Figure $\mathbf{4 c}$ were carried out by suddenly switching on the 1 SUN illumination from the dark steady state condition $(\mathrm{t}=0 \mathrm{~s})$ and monitoring the subsequent rise in photovoltage. The time rise of $\mathrm{V}_{\mathrm{oc}}$ for PSC with Gr$\mathrm{mTiO}_{2}$ was shorter than the reference device. This indicated that an efficient active layer regeneration and/or chargetransfer process between the active and the transport layers occurred in presence of graphene flakes [80]. The fast rises for PSC with $\mathrm{Gr}-\mathrm{mTiO}_{2}$ can be ascribed to a fast filling and stabilization of charge trap states by injected or photogenerated electrons, reducing the availability of trap sites to mediate non-radiative recombination [81]. The rise time of $\mathrm{V}_{\mathrm{oc}}$ obtained for our PSCs evidenced an electron injection improvement at perovskite/ $\mathrm{mTiO}_{2}$ interface when $\mathrm{mTiO}_{2}$ is doped with graphene [82].

According to the electrical parameter statistic graphs (Figure 3), a dual effect of the $\mathrm{Gr}-\mathrm{mTiO}_{2}$ on device performance is evidenced. First, the presence of graphene in the $\mathrm{mTiO}_{2}$ scaffold can deform the perovskite grain due to ferroelectric distortion at graphene/perovskite interfaces which affects the perovskite crystallization process [78, 82]. This can cause an efficient electron injection at the Gr$\mathrm{mTiO}_{2} /$ perovskite interface [58]. Second, graphene can assist the negative carrier transport within the $\mathrm{TiO}_{2}$ layer by increasing electron mobility, which results in increasing the PSCs photocurrent density [83].

In order to further investigate the enhancement of the device performance through the incorporation of graphene in $\mathrm{mTiO}_{2}$, the effects of the absorber layer and conductivity of $\mathrm{TiO}_{2}$ layer were characterized. A four-point probe system was employed to measure the sheet resistance of pristine and Gr$\mathrm{mTiO}_{2}$. As reported in Table 3, Gr- $\mathrm{TiO}_{2}$ showed a $55 \%$ increase of the conductivity with respect to that of pristine $\mathrm{mTiO}_{2}$.

As a further confirmation, sprayed $\mathrm{Gr}-\mathrm{mTiO}_{2}$-based PSCs have shown an improvement in the photocurrent density which is defined by integrating IPCE over the absorption wavelength range. Actually, $\operatorname{IPCE}(\lambda)$ is the product of three factors: light harvesting efficiency $\left(\eta_{\mathrm{LH}}\right)$ depending on the perovskite layer, the quantum yield of charge injection from exited perovskite to ETL and HTL ( $\eta_{\text {INJ }}$ ) and the charge carrier collection efficiency ( $\eta_{\mathrm{COL}}$ ) at the electrodes (IPCE $=$ $\eta_{\text {LH }} \eta_{\text {INJ }} \eta_{\text {COL }}$ ) [84]. In addition, the $\eta_{\text {INJ }}$ is defined as the product between the electron injection $\left(\eta_{\text {Einj }}\right)$ and hole injection $\left(\eta_{\text {Hinj }}\right)$ efficiency, as well as collection efficiency is defined as the product between the electron collection $\left(\eta_{\text {Ecol }}\right)$ and hole collection efficiencies $\eta_{\mathrm{Hcoll}}$ respectively:

$$
\begin{gathered}
\eta_{\mathrm{INJ}}=\eta_{\mathrm{E}_{\mathrm{INJ}}} \eta_{\mathrm{H}} \eta_{\mathrm{INJ}} \\
\eta_{\mathrm{COL}}=\eta_{\mathrm{E}_{\mathrm{COL}}} \eta_{\mathrm{H}_{\mathrm{COL}}}
\end{gathered}
$$

Figure 4d shows the absorption spectra of perovskite grown on both $\mathrm{mTiO}_{2}$ and $\mathrm{Gr}-\mathrm{mTiO}_{2}$ scaffolds, evidencing that they are perfectly overlapped. This means that the modified $\mathrm{Gr}-\mathrm{TiO}_{2}$ layer did not affect the perovskite light harvesting properties. Consequently, since the two structures differed only in the addition of graphene within the ETL, the $\eta_{\mathrm{LH}}, \eta_{\mathrm{Hinj}}$ and $\eta_{\mathrm{Hcoll}}$ can be considered equal for both structures. Therefore, enhancement of IPCE in graphene-based devices can be likely ascribable to higher $\eta_{\text {Einj }}$ at the perovskite/HTL interface and improved $\eta_{E c o l}$ at the PE. Such analysis agrees with the $\mathrm{V}_{\mathrm{OC}}$ rise and $\mathrm{V}_{\mathrm{OC}} / \mathrm{J}_{\mathrm{SC}}$ vs. $\mathrm{P}_{\text {inc }}$ trends previously discussed.

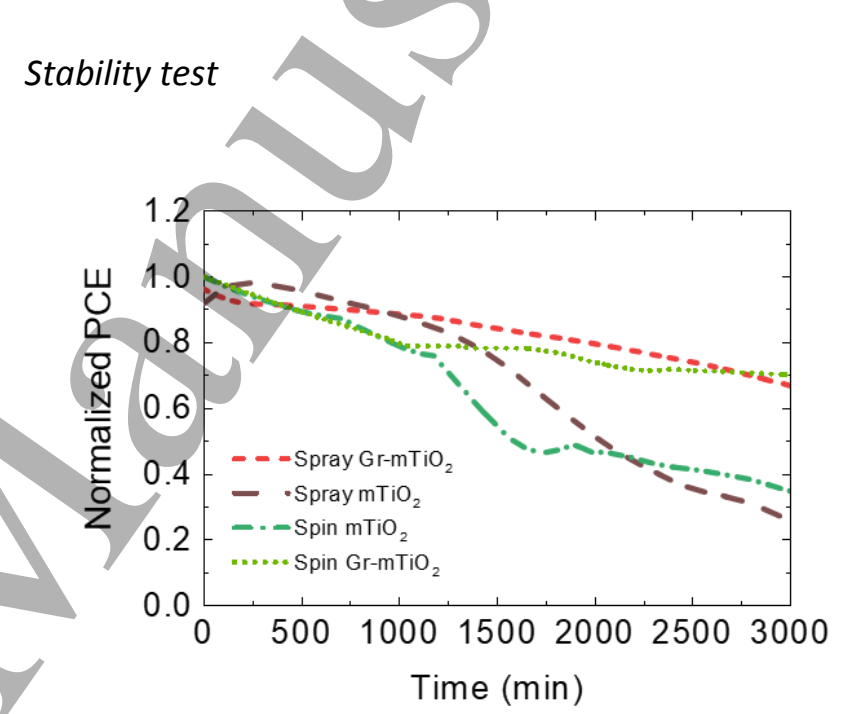

Figure 5. PCE aging trends under prolonged 1 SUN white LED illumination at MPP for the tested device typologies.

One of the most crucial challenges for mesoscopic PSCs is the stability under real working condition [85]. Despite numerous efforts by the scientific community to develop more stable cells, many issues are still opened since perovskite degradation depends strongly on light, moisture, and temperature [86-88].

Based on these considerations, we compared the stability of encapsulated PSCs based on pristine sprayed $\mathrm{mTiO}_{2}$ and $\mathrm{Gr}-$ $\mathrm{mTiO}_{2}$, respectively, by exposing them continuously under 1 SUN illumination for 2 days at $50{ }^{\circ} \mathrm{C}$ and $55 \%$ relative humidity of ambient air. The $\mathrm{I}-\mathrm{V}$ characteristics were progressively acquired during the ageing time at MPP. The extracted electrical parameters are reported in Figure 5, normalized to the value obtained at $\mathrm{t}=0 \mathrm{~min}$. Notably, the cells based on sprayed $\mathrm{Gr}-\mathrm{mTiO}_{2}$ showed a remarkable stability by retaining more than $80 \%$ of the initial PCE value 
after more than $40 \mathrm{~h}$ of the stress test, whereas the PCE of the spray pristine $\mathrm{mTiO}_{2}$ cells decayed by $50 \%$ over the first $25 \mathrm{~h}$.

As discussed in the previous section, the $\mathrm{Gr}-\mathrm{mTiO}_{2}$ has an electrical conductivity that can optimize charge collection [8992] and separation [80,91] at the PE. The improved charge extraction at the PE drastically reduces the trapped charges accumulated at the $\mathrm{mTiO}_{2} /$ perovskite interface. This slows down the perovskite degradation [92]. Moreover, as discussed by Busby et al. [93] through ToF-SIMS measurements, the presence of graphene into the $\mathrm{mTiO}_{2}$ limits the Ti-I bonding preserving a compact $\mathrm{CH}_{3} \mathrm{NH}_{3} \mathrm{PbI}_{3}$ layer upon the lightinduced ageing. We should also point out that $2 \mathrm{D}$ materials can improve thermal stability by reducing surface degradation of perovskite [94].

\section{Conclusion}

The field of perovskite solar cells (PSCs) is rapidly moving toward consolidating deposition processes that can be extended to large-area for industrial exploitations. In this work, we reported that the combined use of automatized spray coating techniques and graphene doping of $\mathrm{mTiO}_{2}$ is an effective strategy to improve photovoltaic performances of PSCs with respect to the conventional, lab-scale device produced by spin coating process. More in detail, the PSC fabricated on a small-area with spray-coated $\mathrm{Gr}-\mathrm{mTiO}_{2}$ has shown an average power conversion efficiency (PCE) of $16.8 \%$ ( $\max 17.5 \%$ ), which is remarkably superior to that obtained for PSC using graphene-free sprayed $(14.3 \%)$ or spin-coated $\mathrm{mTiO}_{2}(15.1 \%)$. These results were also confirmed on large-area cells, which achieved a PCE of [7] $14.96 \%$ using spray-coated $\mathrm{Gr}-\mathrm{mTiO} 2$, against $13.1 \%$ obtained by the reference PSCs. Electro-optical characterizations and transient measurements have shown that graphene doping of $\mathrm{TiO}_{2}$ can improve the electron transport in ETL and charge injection at perovskite/ETL interface. In addition, $\mathrm{Gr}-\mathrm{mTiO}_{2}$ layer strongly affected the stability of PSCs under prolonged (47h) light soaking conditions by enlarging the lifetime of the devices, which retained more than $80 \%$ of the initial PCE value. These results pave the way to realize stabilized mesoscopic perovskite solar modules with a versatile, low-cost and roll-to-roll compatible printing technique.

\section{Acknowledgments}

This project has received funding from the European Union's Horizon 2020 research and innovation programme under grant agreement No. 785219 - GrapheneCore2. A. D. C. gratefully acknowledge the financial support of the Ministry of Education and Science of the Russian Federation in the framework of Increase Competitiveness Program of
NUST "MISiS" (No. K2-2017-025), implemented by a governmental decree dated 16th of March 2013, N 211.

\section{References}

\section{[1] KRICT/UNIST 2018}

[2] Mei A, Li X, Liu L, Ku Z, Liu T, Rong Y, Xu M, Hu M, Chen J, Yang Y, Grätzel M and Han H 2014 A hole-conductor-free, fully printable mesoscopic perovskite solar cell with high stability Science $\mathbf{3 4 5}$ 295

[3] Nah Y-C, Paramasivam I and Schmuki P 2010 Doped $\mathrm{TiO} 2$ and $\mathrm{TiO}_{2}$ Nanotubes: Synthesis and Applications ChemPhysChem 11 2698-713

[4] Ponseca C S, Savenije T J, Abdellah M, Zheng K, Yartsev A, Pascher T, Harlang T, Chabera P, Pullerits T, Stepanov A, Wolf J-P and Sundström V 2014 Organometal Halide Perovskite Solar Cell Materials Rationalized:Ultrafast Charge Generation, High and Microsecond-Long Balanced Mobilities, and Slow Recombination Journal of the American Chemical Society 136 5189-92

[5] Yang W S, Park B-W, Jung E H, Jeon N J, Kim Y C, Lee D U, Shin S S, Seo J, Kim E K, Noh J H and Seok S I 2017 Iodide management in formamidinium-lead-halide-based perovskite layers for efficient solar cells Science $\mathbf{3 5 6} 1376$

[6] Grancini G, Roldán-Carmona C, Zimmermann I, Mosconi E, Lee X, Martineau D, Narbey S, Oswald F, De Angelis F, Graetzel M and Nazeeruddin M K 2017 One-Year stable perovskite solar cells by 2D/3D interface engineering 815684

Yang J, Fransishyn K M and Kelly T L 2016 Comparing the Effect of Mesoporous and Planar Metal Oxides on the Stability of Methylammonium Lead Iodide Thin Films Chemistry of Materials 28 7344-52

[8] Kim H-S and Park N-G 2014 Parameters Affecting I-V Hysteresis of CH3NH3PbI3 Perovskite Solar Cells: Effects of Perovskite Crystal Size and Mesoporous TiO2 Layer The Journal of Physical Chemistry Letters 5 2927-34

[9] Agresti A, Pescetelli S, Palma A L, Del Rio Castillo A E, Konios D, Kakavelakis G, Razza S, Cinà L, Kymakis E, Bonaccorso F and Di Carlo A 2017 Graphene Interface Engineering for Perovskite Solar Modules: $12.6 \%$ Power Conversion Efficiency over $50 \mathrm{~cm} 2$ Active Area ACS Energy Letters 2 279-87

[10] Matteocci F, Cinà L, Di Giacomo F, Razza S, Palma A L, Guidobaldi A, D'Epifanio A, Licoccia S, Brown T M, Reale A and Di Carlo A 2016 High efficiency photovoltaic module based on mesoscopic organometal halide perovskite Progress in Photovoltaics: Research and Applications 24 436-45 [11] Matteocci F, Razza S, Di Giacomo F, Casaluci S, Mincuzzi G, Brown T M, D'Epifanio A, Licoccia S and Di Carlo A 2014 Solid-state solar modules based 
on mesoscopic organometal halide perovskite: a route towards the up-scaling process Physical Chemistry Chemical Physics 16 3918-23

[12] Kim H-S, Lee C-R, Im J-H, Lee K-B, Moehl T, Marchioro A, Moon S-J, Humphry-Baker R, Yum JH, Moser J E, Grätzel M and Park N-G 2012 Lead Iodide Perovskite Sensitized All-Solid-State Submicron Thin Film Mesoscopic Solar Cell with Efficiency Exceeding 9\% Scientific Reports 2591

[13] Huang H, Shi J, Lv S, Li D, Luo Y and Meng Q 2015 Sprayed P25 scaffolds for high-efficiency mesoscopic perovskite solar cells Chemical Communications 51 10306-9

[14] Lee H, Hwang D, Jo S M, Kim D, Seo Y and Kim D Y 2012 Low-Temperature Fabrication of TiO2 Electrodes for Flexible Dye-Sensitized Solar Cells Using an Electrospray Process ACS Applied Materials \& Interfaces 4 3308-15

[15] Kim M-c, Kim B J, Yoon J, Lee J-w, Suh D, Park Ng, Choi M and Jung H S 2015 Electro-spray deposition of a mesoporous $\mathrm{TiO} 2$ charge collection layer: toward large scale and continuous production of high efficiency perovskite solar cells Nanoscale 7 20725-33

[16] Krebs F C 2009 Fabrication and processing of polymer solar cells: A review of printing and coating techniques Solar Energy Materials and Solar Cells 93 394-412

[17] Aziz F and Ismail A F 2015 Spray coating methods for polymer solar cells fabrication: A review Materials Science in Semiconductor Processing 39 416-25

[18] Nga P P, Joachim N B and Pasqualina M S 2005 Spray coating of photoresist for pattern transfer on high topography surfaces Journal of Micromechanics and Microengineering 15691

[19] Reale A, La Notte L, Salamandra L, Polino G, Susanna G, Brown T M, Brunetti F and Di Carlo A 2015 Spray Coating for Polymer Solar Cells: An Upto-Date Overview Energy Technology 3 385-406

[20] Ono L K, Park N-G, Zhu K, Huang W and Qi Y 2017 Perovskite Solar Cells-Towards Commercialization ACS Energy Letters 2 1749-51

[21] Song Z, McElvany C L, Phillips A B, Celik I, Krantz P W, Watthage S C, Liyanage $\mathrm{G} / \mathrm{K}$, Apul D and Heben M J 2017 A technoeconomic analysis of perovskite solar module manufacturing with lowcost materials and techniques Energy \& Environmental Science 10 1297-305

[22] Berry J J, van de Lagemaat J, Al-Jassim M M, Kurtz S, Yan Y and Zhu K 2017 Perovskite Photovoltaics: The Path to a Printable Terawatt-Scale Technology ACS Energy Letters 2 2540-4

[23] Bishop J E, Mohamad D K, Wong-Stringer M, Smith A and Lidzey D G 2017 Spray-cast multilayer perovskite solar cells with an active-area of $1.5 \mathrm{~cm} 2$ Scientific Reports 77962
[31] Yang Z, Zhang S, Li L and Chen $\mathrm{W} 2017$ Research progress on large-area perovski modules Journal of Materiomics 3 231-44

Das S, Yang B, Gu G, Joshi P C, Ivanov I N, Rouleau C M, Aytug T, Geohegan D B and Xiao K 2015 High-Performance Flexible Perovskite Solar Cells by Using a Combination of Ultrasonic Spray-Coating and Low Thermal Budget Photonic Curing ACS Photonics 2 680-6

Samorì P, Palermo V and Feng X 2016 Chemical Approaches to 2D Materials Advanced Materials 28 6027-9

Zhang J, Wang T, Liu P, Liu S, Dong R, Zhuang X, Chen M and Feng X 2016 Engineering water dissociation sites in MoS2 nanosheets for accelerated electrocatalytic hydrogen production Energy \& Environmental Science 9 2789-93

Xia Z, Leonardi F, Gobbi M, Liu Y, Bellani V, Liscio A, Kovtun A, Li R, Feng X, Orgiu E, Samorì P, Treossi E and Palermo V 2016 Electrochemical Functionalization of Graphene at the Nanoscale with Self-Assembling Diazonium Salts ACS Nano 10 7125-34

Najafi L, Bellani S, Oropesa- Nuñez R, Ansaldo A, Prato M, DelRio Castillo Antonio E and Bonaccorso F 2018 Engineered MoSe2- Based Heterostructures for Efficient Electrochemical Hydrogen Evolution Reaction Advanced Energy Materials 01703212 Najafi L, Bellani S, Martín-García B, OropesaNuñez R, Del Rio Castillo A E, Prato M, Moreels I and Bonaccorso F 2017 Solution-Processed Hybrid Graphene Flake/2H-MoS2 Quantum Dot Heterostructures for Efficient Electrochemical Hydrogen Evolution Chemistry of Materials 29 5782-6

Chen S and Shi G 2017 Two-Dimensional Materials for Halide Perovskite-Based Optoelectronic Devices Advanced Materials 29 1605448-n/a

Yang J, Voiry D, Ahn Seong J, Kang D, Kim Ah Y, Chhowalla M and Shin Hyeon S 2013 TwoDimensional Hybrid Nanosheets of Tungsten Disulfide and Reduced Graphene Oxide as Catalysts for Enhanced Hydrogen Evolution Angewandte Chemie International Edition 52 13751-4

Bonaccorso F, Colombo L, Yu G, Stoller M, Tozzini V, Ferrari A C, Ruoff R S and Pellegrini V 2015 Graphene, related two-dimensional crystals, and hybrid systems for energy conversion and storage Science $\mathbf{3 4 7}$

Bonaccorso F, Lombardo A, Hasan T, Sun Z, Colombo L and Ferrari A C 2012 Production and processing of graphene and $2 \mathrm{~d}$ crystals Materials Today 15 564-89

Li S-L, Tsukagoshi K, Orgiu E and Samori P 2016 Charge transport and mobility engineering in twodimensional transition metal chalcogenide semiconductors Chemical Society Reviews 45 118-51 
[36] Yang S, Brüller S, Wu Z-S, Liu Z, Parvez K, Dong R, Richard F, Samorì P, Feng X and Müllen K 2015 Organic Radical-Assisted Electrochemical Exfoliation for the Scalable Production of HighQuality Graphene Journal of the American Chemical Society 137 13927-32

[37] Nicolosi V, Chhowalla M, Kanatzidis M G, Strano M S and Coleman J N 2013 Liquid Exfoliation of Layered Materials Science 340

[38] Ciesielski A, Haar S, El Gemayel M, Yang H, Clough J, Melinte G, Gobbi M, Orgiu E, Nardi Marco V, Ligorio G, Palermo V, Koch N, Ersen O, Casiraghi C and Samorì P 2014 Harnessing the Liquid- Phase Exfoliation of Graphene Using Aliphatic Compounds: A Supramolecular Approach Angewandte Chemie International Edition 53 1035561

[39] Haar S, Ciesielski A, Clough J, Yang H, Mazzaro R, Richard F, Conti S, Merstorf N, Cecchini M, Morandi V, Casiraghi C and Samorì P 2014 A Supramolecular Strategy to Leverage the LiquidPhase Exfoliation of Graphene in the Presence of Surfactants: Unraveling the Role of the Length of Fatty Acids Small 11 1691-702

[40] Parvez K, Wu Z-S, Li R, Liu X, Graf R, Feng X and Müllen K 2014 Exfoliation of Graphite into Graphene in Aqueous Solutions of Inorganic Salts Journal of the American Chemical Society 1366083 91

[41] Haar S, El Gemayel M, Shin Y, Melinte G, Squillaci M A, Ersen O, Casiraghi C, Ciesielski A and Samor P 2015 Enhancing the Liquid-Phase Exfoliation of Graphene in Organic Solvents upon Addition of nOctylbenzene Scientific Reports 516684

[42] Ciesielski A and Samori P 2014 Graphene via sonication assisted liquid-phase exfoliation Chemical Society Reviews 43 381-98

[43] Parvez K, Yang S, Feng X and Müllen K 2015 Exfoliation of graphene via wet chemical routes Synthetic Metals 210 123-32

[44] Bonaccorso F, Bartolotta A, Coleman J N and Backes C 2016 2D-Crystal-Based Functional Inks Advanced Materials 28 6136-66

[45] Ciesielski A and Samorì P 2016 Supramolecular Approaches to Graphene: From Self- Assembly to Molecule- Assisted Liquid- Phase Exfoliation Advanced Materials 28 6030-51

[46] Bellani S, Najafi L, Capasso A, Del Rio Castillo A E, Antognazza M R and Bonaccorso F 2017 Few-layer MoS2 flakes as a hole-selective/ayer for solutionprocessed hybrid organic hydrogen-evolving photocathodes Journal of Materials Chemistry A $\mathbf{5}$ 4384-96

[47] Bellani S, Najafi L, Martín-García B, Ansaldo A, Del Rio Castillo A E, Prato M, Moreels I and Bonaccorso F 2017 Graphene-Based Hole-Selective Layers for High-Efficiency, Solution-Processed, Large-Area, Flexible, Hydrogen-Evolving Organic
Photocathodes The Journal of Physical Chemistry C 121 21887-903

[48] Li D, Müller M B, Gilje S, Kaner R B and Wallace G G 2008 Processable aqueous dispersions of graphene nanosheets Nature Nanotechnology 3101

[49] Casaluci S, Gemmi M, Pellegrini V, Di Carlo A and Bonaccorso F 2016 Graphene-based large area dyesensitized solar cell modules Nanoscale 8 5368-78

[50] Secor E B, Prabhumirashi P L, Puntambekar K, Geier M L and Hersam M C 2013 Inkjet Printing of High Conductivity, Flexible Graphene Patterns The Journal of Physical Chemistry Letters 4 1347-51

[51] Torrisi F, Hasan T, Wu W, Sun Z, Lombardo A, Kulmala T S, Hsieh G-W, Jung S, Bonaccorso F, Paul P J, Chu D and Ferrari A C 2012 Inkjet-Printed Graphene Electronics ACS Nano 6 2992-3006

[52] Secor Ethan B, Lim S, Zhang H, Frisbie C D, Francis Lorraine F and Hersam Mark C 2014 Gravure Printing of Graphene for Large- area Flexible Electronics Advanced Materials 26 4533-8

[53] Capasso A, Del Rio Castillo A E, Sun H, Ansaldo A, Pellegrini V and Bonaccorso F 2015 Ink-jet printing of graphene for flexible electronics: An environmentally-friendly approach Solid State Communications 224 53-63

[54] Wang J T-W, Ball J M, Barea E M, Abate A, Alexander-Webber J A, Huang J, Saliba M, MoraSero I, Bisquert J, Snaith H J and Nicholas R J 2014 Low-Temperature Processed Electron Collection Layers of Graphene/TiO2 Nanocomposites in Thin Film Perovskite Solar Cells Nano Letters 14 724-30 Agresti A, Pescetelli S, Cinà L, Konios D, Kakavelakis G, Kymakis E and Carlo A D 2016 Efficiency and Stability Enhancement in Perovskite Solar Cells by Inserting Lithium-Neutralized Graphene Oxide as Electron Transporting Layer Advanced Functional Materials 26 2686-94

[56] Zhu Z, Ma J, Wang Z, Mu C, Fan Z, Du L, Bai Y, Fan L, Yan H, Phillips D L and Yang S 2014 Efficiency Enhancement of Perovskite Solar Cells through Fast Electron Extraction: The Role of Graphene Quantum Dots Journal of the American Chemical Society 136 3760-3

[57] Han G S, Song Y H, Jin Y U, Lee J-W, Park N-G, Kang B K, Lee J-K, Cho I S, Yoon D H and Jung H S 2015 Reduced Graphene Oxide/Mesoporous TiO2 Nanocomposite Based Perovskite Solar Cells ACS Applied Materials \& Interfaces 7 23521-6

[58] Agresti A, Pescetelli S, Taheri B, Del Rio Castillo A E, Cinà L, Bonaccorso F and Di Carlo A 2016 Graphene-Perovskite Solar Cells Exceed $18 \%$ Efficiency: A Stability Study ChemSusChem 92609 19

[59] Petridis C, Kakavelakis G and Kymakis E 2018 Renaissance of graphene-related materials in photovoltaics due to the emergence of metal halide perovskite solar cells Energy \& Environmental Science 
[60] Del Rio Castillo A E, Pellegrini V, Ansaldo A, Ricciardella F, Sun H, Marasco L, Buha J, Dang Z, Gagliani L, Lago E, Curreli N, Gentiluomo S, Palazon F, Prato M, Oropesa-Nuñez R, Toth P S, Mantero E, Crugliano M, Gamucci A, Tomadin A, Polini M and Bonaccorso F 2018 High-yield production of 2D crystals by wet-jet milling Materials Horizons

[61] Sun H, Del Rio Castillo A E, Monaco S, Capasso A, Ansaldo A, Prato M, Dinh D A, Pellegrini V, Scrosati B, Manna L and Bonaccorso F 2016 Binder-free graphene as an advanced anode for lithium batteries Journal of Materials Chemistry A 4 6886-95

[62] Yaghoobi Nia N, Zendehdel M, Cina L, Matteocci F and Di Carlo A 2018 A crystal engineering approach for scalable perovskite solar cells and module fabrication: a full out of glove box procedure Journal of Materials Chemistry A 6 659-71

[63] Lee J-W, Lee T-Y, Yoo P J, Gratzel M, Mhaisalkar $\mathrm{S}$ and Park N-G 2014 Rutile TiO2-based perovskite solar cells Journal of Materials Chemistry A 2 92519

[64] Salim T, Sun S, Abe Y, Krishna A, Grimsdale A C and Lam Y M 2015 Perovskite-based solar cells: impact of morphology and device architecture on device performance Journal of Materials Chemistry A 3 8943-69

[65] Chen D, Jordan E H and Gell M 2008 Porous TiO2 coating using the solution precursor plasma spray process Surface and Coatings Technology 2026113 9

[66] Kout A and Müller H 2009 Parameter optimization for spray coating Advances in Engineering Software 40 1078-86

[67] Zhu Lifeng S J, Li Dongmei, Meng Qingbo 2015 Effect of Mesoporous TiO2 Layer Thickness on the Cell Performance of Perovskite Solar Cells Acta Chim. Sinica 73 261-6

[68] Lee D G, Kim M-c, Kim B J, Kim D H, Lee S M, Choi M, Lee S and Jung H S 2017 Effect of TiO2 particle size and layer thickness on mesoscopic perovskite solar cells Applied Surface Science

[69] Hou X, Pan L, Huang S, Wei O-Y and Chen X 2017 Enhanced Efficiency and stability of Perovskite Solar Cells using Porous Hierarchical TiO2 Nanostructures of Scattered Distribution as Scaffold Electrochimica Acta 236 351-8

[70] Abdi-Jalebi M, Dar M I, Sadhanala A, Senanayak S P, Giordano F, Zakeeruddin S M, Grätzel M and Friend R H 2016 Impact of a Mesoporous TitaniaPerovskite Interface on the Performance of Hybrid Organic-Inorganic Perovskite Solar Cells The Journal of Physical Chemistry Letters 7 3264-9

[71] Sun X, Xu J, Xiao L, Chen J, Zhang B, Yao J and Dai S 2017 Influence of the Porosity of the TiO2 Film on the Performance of the Perovskite Solar Cell International Journal of Photoenergy 201710
Knorr F J, Mercado C C and McHale J L 2008 TrapState Distributions and Carrier Transport in Pure and Mixed-Phase TiO2: Influence of Contacting Solvent and Interphasial Electron Transfer The Journal of Physical Chemistry C 112 12786-94

[73] Zhang X, Wu Y, Huang Y, Zhou Z and Shen S 2016 Reduction of oxygen vacancy and enhanced efficiency of perovskite solar cell by doping fluorine into TiO2 Journal of Alloys and Compounds $\mathbf{6 8 1}$ 191-6

[74] Ng Y H, Lightcap I V, Goodwin K, Matsumura M and Kamat P V 2010 To What Extent Do Graphene Scaffolds Improve the Photovoltaic and Photocatalytic Response of $\mathrm{TiO} 2$ Nanostructured Films? The Journal of Physical Chemistry Letters 1 2222-7

[75] Im J-H, Jang I-H, Pellet N, Grätzel M and Park N-G 2014 Growth of $\mathrm{CH} 3 \mathrm{NH} 3 \mathrm{PbI} 3$ cuboids with controlled size for high-efficiency perovskite solar cells Nat Nano 9 927-32

[76] Kumar M H, Dharani S, Leong W L, Boix P P, Prabhakar R R, Baikie T, Shi C, Ding H, Ramesh R, Asta M, Graetzel M, Mhaisalkar S G and Mathews N 2014 Lead-Free Halide Perovskite Solar Cells with High Photocurrents Realized Through Vacancy Modulation Advanced Materials 26 7122-7

[77] Mallajosyula A T, Fernando K, Bhatt S, Singh A, Alphenaar B W, Blancon J-C, Nie W, Gupta G and Mohite A D 2016 Large-area hysteresis-free perovskite solar cells via temperature controlled doctor blading under ambient environment Applied Materials Today 3 96-102

Volonakis G and Giustino F 2015 Ferroelectric Graphene-Perovskite Interfaces The Journal of Physical Chemistry Letters 6 2496-502

[79] Katz E A, Mescheloff A, Visoly-Fisher I and Galagan Y 2016 Light intensity dependence of External Quantum Efficiency of fresh and degraded organic photovoltaics Solar Energy Materials and Solar Cells 144 273-80

[80] Capasso A, Matteocci F, Najafi L, Prato M, Buha J, Cinà L, Pellegrini V, Carlo A D and Bonaccorso F 2016 Few-Layer MoS2 Flakes as Active Buffer Layer for Stable Perovskite Solar Cells Advanced Energy Materials 6 1600920-n/a

[81] Cacovich S, Cina L, Matteocci F, Divitini G, Midgley P A, Di Carlo A and Ducati C 2017 Gold and iodine diffusion in large area perovskite solar cells under illumination Nanoscale 9 4700-6

[82] Biccari F, Gabelloni F, Burzi E, Gurioli M, Pescetelli S, Agresti A, Del Rio Castillo A E, Ansaldo A, Kymakis E, Bonaccorso F, Di Carlo A and Vinattieri A Graphene-Based Electron Transport Layers in Perovskite Solar Cells: A Step-Up for an Efficient Carrier Collection Advanced Energy Materials 1701349-n/a

[83] Liang Y T, Vijayan B K, Gray K A and Hersam M C 2011 Minimizing Graphene Defects Enhances 
Titania Nanocomposite-Based Photocatalytic Reduction of $\mathrm{CO} 2$ for Improved Solar Fuel Production Nano Letters 11 2865-70

[84] Halme J, Boschloo G, Hagfeldt A and Lund P 2008 Spectral Characteristics of Light Harvesting, Electron Injection, and Steady-State Charge Collection in Pressed TiO2 Dye Solar Cells The Journal of Physical Chemistry C 112 5623-37

[85] Qiu L, Ono L K and Qi Y 2018 Advances and challenges to the commercialization of organicinorganic halide perovskite solar cell technology Materials Today Energy 7 169-89

[86] Hwang I, Jeong I, Lee J, Ko M J and Yong K 2015 Enhancing Stability of Perovskite Solar Cells to Moisture by the Facile Hydrophobic Passivation ACS Applied Materials \& Interfaces 7 17330-6

[87] Kim N-K, Min Y H, Noh S, Cho E, Jeong G, Joo M, Ahn S-W, Lee J S, Kim S, Ihm K, Ahn H, Kang Y, Lee H-S and Kim D 2017 Investigation of Thermally Induced Degradation in $\mathrm{CH} 3 \mathrm{NH} 3 \mathrm{PbI} 3$ Perovskite Solar Cells using In-situ Synchrotron Radiation Analysis Scientific Reports 74645

[88] Jin J, Chen C, Li H, Cheng Y, Xu L, Dong B, Song $\mathrm{H}$ and Dai Q 2017 Enhanced Performance and Photostability of Perovskite Solar Cells by
Introduction of Fluorescent Carbon Dots ACS Applied Materials \& Interfaces 9 14518-24

[89] Manga K K, Wang S, Jaiswal M, Bao Q and Loh K P 2010 High-Gain Graphene-Titanium Oxide Photoconductor Made from Inkjet Printable Ionic Solution Advanced Materials 22 5265-70

[90] Wen Y, Ding H and Shan Y 2011 Preparation and visible light photocatalytic activity of $\mathrm{Ag} / \mathrm{TiO} 2 /$ graphene nanocomposite Nanoscale $\mathbf{3}$ 4411-7

[91] Bell N J, Ng Y H, Du A, Coster H, Smith S C and Amal R 2011 Understanding the Enhancement in Photoelectrochemical Properties of Photocatalytically Prepared TiO2-Reduced Graphene Oxide Composite The Journal of Physical Chemistry C 115 6004-9

Pathak S K, Abate A, Ruckdeschel P, Roose B, Gödel K C, Vaynzof Y, Santhala A, Watanabe S-I, Hollman D J, Noel N, Sepe A, Wiesner U, Friend R, Snaith H J and Steiner U 2014 Performance and Stability Enhancement of Dye-Sensitized and Perovskite Solar Cells by $\mathrm{Al}$ Doping of $\mathrm{TiO} 2$ Advanced Functional Materials 24 6046-55 